\title{
Postpartum Patient Navigation and Postpartum Weight Retention
}

\author{
Michelle A. Kominiarek, MD, MS ${ }^{1}$ Sydney Summerlin, BA ${ }^{1} \quad$ Noelle G. Martinez, MPH ${ }^{1}$ \\ Lynn M. Yee, MD, MPH ${ }^{1}$ \\ ${ }^{1}$ Division of Maternal-Fetal Medicine, Department of Obstetrics and \\ Gynecology of Northwestern University, Chicago, Illinois \\ Am J Perinatol Rep 2019;9:e292-e297. \\ Address for correspondence Michelle A. Kominiarek, MD, MS, \\ Division of Maternal-Fetal Medicine, Department of Obstetrics and \\ Gynecology, Northwestern University, 250 East Superior Street, \\ Suite 05-2149, Chicago, IL 60611 (e-mail: mkominia@nm.org).
}

\begin{abstract}
\section{Keywords}

- gestational weight gain

- patient navigation

- postpartum weight retention
\end{abstract}

Objective This study aimed to evaluate postpartum weight retention (PPWR) among women who participated in a postpartum patient navigation (PN) program.

Study Design English-speaking pregnant or postpartum women receiving publiclyfunded prenatal care at a hospital-based clinic were invited to receive PN services through 12 weeks postpartum. Women were eligible for this analysis if height and weight values were available. Weights at 4 to 12 weeks and up to 12 months postpartum were compared in PN and non-PN historical-control groups and analyzed as mean PPWR (difference from prepregnancy weight) and categorically as PPWR $>5 \mathrm{~kg}$.

Results Among the 311 women, 152 participated in the PN program and 159 were historical controls. There were no differences in age, race and ethnicity, prepregnancy body mass index (BMI), nulliparity, and preterm birth between the groups $(p>0.05)$. At 4 to 12 weeks postpartum, mean PPWR ( $4.0 \pm 6.7$ vs. $2.7 \pm 6.3 \mathrm{~kg}, p=0.06)$ and PPWR $>5 \mathrm{~kg}$ (61/144 [42\%] vs. 50/145 [34\%], $p=0.15)$ did not differ between groups. Similarly, up to 12 months postpartum, mean PPWR ( $4.5 \pm 7.1$ vs. $5.0 \pm 7.5 \mathrm{~kg}, p=0.59)$ and PPWR $>5 \mathrm{~kg}$ (22/50 [44\%] vs. 30/57 [53\%], $p=0.55$ ) did not differ between groups.

Conclusion Although PN is a promising intervention to improve women's health care utilization and other associated health outcomes, in this particular navigation program, participation was not associated with PPWR at 4 to 12 weeks and up to 12 months postpartum.
Nearly $50 \%$ of pregnant women are estimated to exceed recommendations for gestational weight gain (GWG) goals and up to $75 \%$ of women weigh more than their prepregnancy weight at 1 year postpartum. ${ }^{1,2}$ Postpartum weight retention, or the failure to lose weight gained during pregnancy, increases the risk for adverse outcomes in future pregnancies, such as stillbirth and large for gestational age infants. ${ }^{3}$ Such pregnancy weight changes can also dramatically influence a woman's long-term health by increasing her risk for developing comorbidities, such as hypertension and diabetes. ${ }^{4}$

During pregnancy, many women are motivated to change their health behaviors to have a healthy pregnancy., ${ }^{5,6}$ After delivery, a "natural period of redefinition" also occurs as a result of physiological, social, and psychological changes. ${ }^{7}$ Therefore, the postpartum period is also recognized as a window of opportunity for health behavior change including weight management, but women face many challenges with new roles and responsibilities as mothers with unpredictable schedules, thereby making it difficult to prioritize their own health. Of note, the prevalence of overweight and obesity was the highest among minority nonpregnant women in 2015 to 2016 (54.8\% for non-Hispanic blacks and 50.6\% for Hispanics compared with $38.0 \%$ for non-Hispanic whites) and associations between postpartum weight retention among non-Hispanic black and low-income women have been reported. ${ }^{1,8}$ Given the important long-term health implications of received

April 27, 2019

accepted after revision

June 28, 2019
DOI https://doi.org/

10.1055/s-0039-1694700. ISSN 2157-6998.
Copyright $\odot 2019$ by Thieme Medical

Publishers, Inc., 333 Seventh Avenue, New York, NY 10001, USA. Tel: +1(212) 584-4662.
License terms

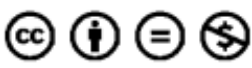


postpartum weight retention and the potential for increased patient engagement in this early postpartum period, ${ }^{9}$ interventions during these times are needed, especially for lowincome and minority women.

Patient navigation is the use of trained personnel to mitigate barriers and promote health care access and engagement. ${ }^{10}$ Navigation has been suggested as one mechanism to improve health care utilization after birth. Patient navigators have a well-established role in oncology; however, the concept of patient navigation in the prenatal and postpartum periods is more novel. Furthermore, patient navigators may be a potential resource for weight management interventions, given their frequent patient interactions that involve counseling, resource provisions, and assistance with self-care, yet the concept has also not been studied in pregnancy and postpartum-related weight management interventions. The objective of this study was to evaluate postpartum weight retention at 6 weeks and up to 12 months among women who participated in a postpartum patient navigation program designed to improve uptake of postpartum care in a population of low-income, largely minority women. Given the successes of this program related to postpartum health care utilization and frequency of contraception uptake, depression screening, and vaccination, ${ }^{11}$ we sought to investigate whether the positive changes in health care utilization from navigation also carried over to other health behaviors, such as weight management. Consequently, we hypothesized that women in the navigated cohort would have less-postpartum weight retention at the 6 week and any subsequent follow-up visits compared with the historical-control group.

\section{Materials and Methods}

The Navigating New Motherhood (NNM) program was adapted from a well-studied cancer navigation model to the postpartum period for women receiving prenatal care at the Northwestern Memorial Hospital obstetrics and gynecology practice that primarily provides care for low-income women receiving publicly funded prenatal care. ${ }^{11}$ The methods for the NNM program, as well as the comparison of outcomes to a historicalcontrol group have been previously published. ${ }^{11}$ Briefly, the inclusion criteria were delivery in the second trimester or later at the intervention site, $>18$ years, English speaking, and HIV negative. The patient navigator received extensive training with respect to postpartum care logistical and supportive needs via in-person meetings with nurses, medical assistants, and physicians. The navigator also worked with the social worker and lactation consultant and ultimately integrated herself into the clinic environment. The navigator did not receive nutrition or exercise-specific training or training specifically on weight-management navigation.

The navigator approached eligible participants in their third trimester of pregnancy in the outpatient office or shortly after delivery in the hospital from 2015 to 2016. After obtaining consent and performing intake surveys, the navigator scheduled the participants' 6 week postpartum visit and any other recommended visits and sent scheduled reminders 1 week after delivery, 1 week before the appointment, and 1 day before the appointment. The navigator additionally provided social and logistical support to postpartum women as needed, connected patients with health care providers, and provided linkage to local resources. Brief written and verbal counseling about the benefits of breastfeeding and contraception were provided during the inpatient visit as well. During the 6 weeks' postpartum visit, the navigator met with each participant, ensured that all needs were met, and coordinated future appointments. If participants did not return for the visit, the navigator contacted them weekly up to 12 weeks postpartum. The majority of the participants communicated with the navigator via text messages with a minimum of three contact points with the navigator, but most women had three to eight episodes of contact, as previously described. ${ }^{12}$

In this secondary analysis, participants were eligible for inclusion if height and weight values prior to pregnancy, at delivery, and within 12 months of delivery were available for abstraction from the electronic medical record. Gestational weight gain, defined as the difference between the selfreported prepregnancy weight and the weight at delivery, was compared between groups as a categorical variable (inadequate, adequate, and excessive; weight gain vs. loss) according to the 2009 National Academy of Sciences guidelines (28-40 pounds for body mass index $[\mathrm{BMI}]<18.5 \mathrm{~kg} / \mathrm{m}^{2}, 25-35$ pounds for BMI: $18.5-24.9 \mathrm{~kg} / \mathrm{m}^{2}, 15-25$ pounds for BMI: $25.0-29.9 \mathrm{~kg} / \mathrm{m}^{2}$, and $11-20$ pounds for $\left.\mathrm{BMI} \geq 30 \mathrm{~kg} / \mathrm{m}^{2}\right){ }^{4}$ All weight data were abstracted from the electronic medical record used for clinical care.

The primary outcome was postpartum weight retention at the postpartum visit, analyzed as a difference from the selfreported prepregnancy weight to the weight at the postpartum visit. Additionally, this primary outcome was categorized as postpartum weight retention $>0 \mathrm{~kg}$ (any weight retention) and $>5 \mathrm{~kg}$ over prepregnancy weight. Participants typically returned to the clinic for a postpartum visit at approximately 6 weeks; however, for this study we included any outpatient weight measurement that occurred between 4 and 12 weeks postpartum for the primary outcome, whether it occurred during a visit for postpartum or other care (e.g., primary care, nurse visit, or other specialty care).

The secondary outcome was any weight measure up to 12 months postpartum noted in the electronic medical record of this site (i.e., primary care, subsequent obstetricgynecologic care, or any other specialty care). This 12 month weight outcome was analyzed both as a continuous variable and categorically, as for the primary outcome. Women who were identified in the electronic medical record to have become pregnant again before the final endpoint at 12 months after delivery were censored.

Maternal demographics (age, race, ethnicity, and marital status) and clinical characteristics (nulliparity, number of prenatal visits, and gestational age at delivery) including gestational weight gain (inadequate, adequate, and excessive) between the navigated and historical-control participants were compared with Mann-Whitney tests, Fisher's exact tests, and Chi-square tests as appropriate. Similarly, the primary 
(postpartum weight retention at 4-12 weeks) and secondary (postpartum weight retention at 12 weeks-12 months) outcomes were compared with Mann-Whitney tests and Chisquare tests as appropriate. A $p$-value $<0.05$ was considered statistically significant. An a priori power calculation was not performed as the sample size was constrained by the original NNM study cohort.

The study was approved by the institutional review board (IRB) of Northwestern University. All navigated participants signed written informed consent prior to participation. The analysis was completed with STATA Statistical software program.

\section{Results}

From the original cohort of 218 navigated participants and 256 historical controls, 311 total women were eligible for inclusion for this analysis based on having height and weight data (prepregnancy, at delivery, any postpartum visit) available. Of the 311 eligible women, 152 participated in the navigation program and 159 were historical controls. The majority of patients were non-Hispanic black or Hispanic, and approximately one-third were nulliparous. All women received Medicaid-funded prenatal care. There were no differences in age, race and ethnicity, prepregnancy BMI, nulliparity, and timing of initiation of prenatal care ( $p$-value $>0.05$ for all comparisons). Women in the navigation program had fewer numbers of prenatal care visits ( $p$ value $=0.003 ;-$ Table 1 ) .

There were no differences in gestational weight gain classification according to guidelines (20.4 vs. $25.2 \%$ inadequate, 22.4 vs. $27.7 \%$ adequate, 57.2 vs. $47.2 \%$ excessive; $p$-value $>0.05$ ) between navigated and nonnavigated groups. Similarly, there were no differences in obstetrical outcomes between navigated and nonnavigated groups, although women in the navigated cohort were more likely to have neonates who were admitted to the neonatal intensive care unit (-Table 2). Postpartum weight was measured at a median of 6.3 weeks (interquartile range [IQR]: 6.0-7.1) and 24.4 weeks (IQR: 15.6-40.4) for the 4 to 12 weeks and up to 12 months postpartum weight values, respectively.

The primary outcome, postpartum weight retention at 4 to 12 weeks' postpartum, did not differ based on navigation status (-Table 3). Neither mean postpartum weight retention $(4.0 \pm 6.7 \mathrm{~kg}$ for navigated vs. $2.7 \pm 6.3 \mathrm{~kg}$ for nonnavigated, $\quad p$-value $=0.11$ ) nor postpartum weight retention $>5 \mathrm{~kg}$ ( $42.4 \%$ for navigated vs. $34.7 \%$ for nonnavigated, $p$-value $=0.15$ ) differed between groups (-Table 3). Findings also did not differ for postpartum weight retention $>0 \mathrm{~kg}$.

Similarly, at up to 12 months postpartum, mean postpartum weight retention $(4.5 \pm 7.1 \mathrm{~kg}$ for navigated vs. $5.0 \pm 7.5 \mathrm{~kg}$ for nonnavigated, $p$-value $=0.59)$ and postpartum weight retention $>5 \mathrm{~kg}$ ( $44.0 \%$ for navigated vs. $52.6 \%$ for nonnavigated, $p$-value $=0.55$ ) did not differ between groups (-Table 3). Findings also did not differ for postpartum weight retention $>0 \mathrm{~kg}$.
Table 1 Maternal demographic and clinical characteristics for navigating new motherhood and historical control

\begin{tabular}{|c|c|c|c|}
\hline $\begin{array}{l}\text { Variable } \\
(\text { mean } \pm \text { SD or } n \%)\end{array}$ & $\begin{array}{l}\text { Navigated } \\
(n=152)\end{array}$ & $\begin{array}{l}\text { Historical } \\
\text { control } \\
(n=159)\end{array}$ & $p$-Value \\
\hline Age at delivery (y) & $28.9 \pm 4.9$ & $29.4 \pm 5.8$ & 0.39 \\
\hline Hispanic & $51(30.8)$ & $49(33.6)$ & 0.61 \\
\hline \multicolumn{3}{|l|}{ Race } & \multirow[t]{5}{*}{0.55} \\
\hline White & $68(44.7)$ & $61(38.4)$ & \\
\hline Black & $75(49.3)$ & $87(54.7)$ & \\
\hline Asian & $8(5.3)$ & $8(5.0)$ & \\
\hline Other & $1(0.7)$ & $3(1.9)$ & \\
\hline $\begin{array}{l}\text { Mean prepregnancy } \\
\text { BMI }\left(\mathrm{kg} / \mathrm{m}^{2}\right)\end{array}$ & $29.8 \pm 8.0$ & $28.6 \pm 7.5$ & 0.22 \\
\hline Underweight & $7(4.6)$ & $7(4.4)$ & \multirow[t]{4}{*}{0.45} \\
\hline Normal & $44(28.9)$ & $50(31.4)$ & \\
\hline Overweight & $31(20.4)$ & $42(26.4)$ & \\
\hline Obese & $70(46.1)$ & $60(37.7)$ & \\
\hline Married & 50 (32.9) & $49(30.8)$ & 0.04 \\
\hline Nullipara & $49(32.2)$ & $49(30.8)$ & 0.79 \\
\hline $\begin{array}{l}\text { Total number of } \\
\text { prenatal care visits }\end{array}$ & $9.2 \pm 3.3$ & $10.3 \pm 3.1$ & 0.003 \\
\hline $\begin{array}{l}\text { 1st trimester care } \\
(\leq 13 \mathrm{wk})\end{array}$ & $74(48.7)$ & $93(58.5)$ & 0.08 \\
\hline \multicolumn{3}{|l|}{ Smoking } & \multirow[t]{5}{*}{0.14} \\
\hline Current & $9(5.9)$ & $7(4.4)$ & \\
\hline Prior & $28(18.4)$ & 19 (11.9) & \\
\hline Never & $113(74.3)$ & $133(83.6)$ & \\
\hline Missing & $2(1.3)$ & 0 & \\
\hline $\begin{array}{l}\text { Antepartum } \\
\text { depression } \\
(\mathrm{PHQ} \geq 9) \\
\end{array}$ & & & \multirow[t]{4}{*}{0.29} \\
\hline Yes & $25(16.4)$ & $19(12.0)$ & \\
\hline No & $120(79.0)$ & $136(85.5)$ & \\
\hline Missing & $7(4.6)$ & $4(2.5)$ & \\
\hline $\begin{array}{l}\text { Diabetes } \\
\text { (prepregnancy } \\
\text { and gestational) }\end{array}$ & $25(16.4)$ & $30(18.9)$ & 0.58 \\
\hline $\begin{array}{l}\text { Antenatal nutrition } \\
\text { consult }^{\mathrm{a}}\end{array}$ & $31(20.4)$ & $29(18.2)$ & 0.52 \\
\hline
\end{tabular}

Abbreviations: BMI, body mass index; PHQ9, patient health questionnaire-9; SD, standard deviation.

Note: bold values indicate statistical significance.

${ }^{a} n=1$ missing.

\section{Discussion}

Although patient navigation has been demonstrated to improve multiple health services outcomes, health outcomes, and patient-reported outcomes in oncology and is a promising intervention to improve postpartum women's health care utilization, in this study of predominantly low- 
Table 2 Antenatal and delivery outcomes for navigating new motherhood and historical control

\begin{tabular}{|c|c|c|c|}
\hline $\begin{array}{l}\text { Variable } \\
\text { (mean } \pm \text { SD } \\
\text { or } n \% \text { ) }\end{array}$ & $\begin{array}{l}\text { Navigated } \\
(n=152)\end{array}$ & $\begin{array}{l}\text { Historical } \\
\text { control } \\
(n=159)\end{array}$ & $p$-Value \\
\hline $\begin{array}{l}\text { Mean gestational } \\
\text { weight gain }(\mathrm{kg})\end{array}$ & $13.4 \pm 7.2$ & $12.7 \pm 6.9$ & 0.44 \\
\hline $\begin{array}{l}\text { Inadequate } \\
\text { gestational } \\
\text { weight gain }\end{array}$ & $31(20.4)$ & $40(25.2)$ & \multirow[t]{3}{*}{0.21} \\
\hline $\begin{array}{l}\text { Adequate } \\
\text { gestational } \\
\text { weight gain }\end{array}$ & $34(22.4)$ & $44(27.7)$ & \\
\hline $\begin{array}{l}\text { Excessive } \\
\text { gestational } \\
\text { weight gain }\end{array}$ & $87(57.2)$ & $75(47.2)$ & \\
\hline $\begin{array}{l}\text { Gestational } \\
\text { hypertension } \\
\text { or preeclampsia }\end{array}$ & $18(11.8)$ & $12(7.6)$ & 0.20 \\
\hline $\begin{array}{l}\text { Mean gestational } \\
\text { age at delivery (wk) }\end{array}$ & $38.6 \pm 2.0$ & $38.3 \pm 2.6$ & 0.12 \\
\hline $\begin{array}{l}\text { Preterm delivery } \\
\text { (<37 wk) }\end{array}$ & $19(12.5)$ & $24(15.1)$ & 0.51 \\
\hline Vaginal delivery & $101(66.5)$ & $103(64.8)$ & 0.76 \\
\hline $\begin{array}{l}\text { Postpartum } \\
\text { hemorrhage }^{\text {a }}\end{array}$ & $8(5.3)$ & $11(6.9)$ & 0.52 \\
\hline $\begin{array}{l}\text { Postpartum } \\
\text { readmission }\end{array}$ & $3(2.0)$ & $3(1.9)$ & 0.96 \\
\hline Birthweight (g) & $3198 \pm 549$ & $3130 \pm 649$ & 0.35 \\
\hline NICU admission ${ }^{\mathrm{b}}$ & $27(17.8)$ & $13(8.2)$ & 0.02 \\
\hline Postpartum visit ${ }^{\mathrm{C}}$ & $150(98.7)$ & $153(96.2)$ & 0.17 \\
\hline $\begin{array}{l}\text { Breastfeeding at } \\
\text { postpartum visit }\end{array}$ & $76(50.0)$ & $85(56.7)$ & 0.14 \\
\hline $\begin{array}{l}\text { Depression at } \\
\text { postpartum visit }\end{array}$ & $3(1.9)$ & $11(7.2)$ & 0.02 \\
\hline
\end{tabular}

Abbreviations: NICU, neonatal intensive care unit; SD, standard deviation.

Note: bold values indicate statistical significance.

apostpartum hemorrhage was defined as $>500$ cc for a vaginal delivery or $>1,000 \mathrm{cc}$ for a cesarean delivery.

$b_{n}=2$ missing.

'Postpartum visit defined as a visit specifically for postpartum care as opposed to primary or other specialty care.

${ }^{d} n=3$ missing.

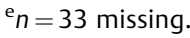

income minority women, participation in postpartum patient navigation was not associated with postpartum weight retention at 4 to 12 weeks. Similarly, in the subgroup of women who had subsequent weights available at this site up to 12 months postpartum, postpartum weight retention also did not differ between women who received intensive postpartum patient navigation services versus those from the historical control group.

Prevention of postpartum weight retention is essential for promotion of long-term health. ${ }^{3}$ Mean postpartum weight retention typically ranges from 0.5 to $4 \mathrm{~kg}$ and a value $>5 \mathrm{~kg}$
Table 3 Postpartum weight outcomes for navigating new motherhood and historical control

\begin{tabular}{|l|l|l|l|}
\hline $\begin{array}{l}\text { Variable } \\
\text { (mean } \pm \text { SD or } \boldsymbol{n} \text { \%) }\end{array}$ & Navigated & $\begin{array}{l}\text { Historical } \\
\text { control }\end{array}$ & $p$-Value \\
\hline $\begin{array}{l}\text { At } 4 \text { to } 12 \text { weeks } \\
\text { of postpartum }\end{array}$ & $n=144$ & $N=145$ & \\
\hline Mean weight $(\mathrm{kg})$ & $82.7 \pm 21.7$ & $78.2 \pm 20.3$ & 0.06 \\
\hline Mean PPWR $(\mathrm{kg})$ & $4.0 \pm 6.7$ & $2.7 \pm 6.3$ & 0.11 \\
\hline PPWR $>5 \mathrm{~kg}$ & $61(42.4)$ & $50(34.7)$ & 0.18 \\
\hline PPWR $>0 \mathrm{~kg}$ & $109(75.7)$ & $94(65.2)$ & 0.05 \\
\hline $\begin{array}{l}\text { At } 12 \text { weeks, } \\
\text { up to } 12 \text { months } \\
\text { of postpartum }\end{array}$ & $n=50$ & $n=57$ & \\
\hline Mean weight $(\mathrm{kg})$ & $85.4 \pm 26.3$ & $81.5 \pm 23.5$ & 0.38 \\
\hline Mean PPWR $(\mathrm{kg})$ & $4.5 \pm 7.1$ & $5.0 \pm 7.5$ & 0.59 \\
\hline PPWR $>5 \mathrm{~kg}$ & $22(44.0)$ & $30(52.6)$ & 0.37 \\
\hline PPWR $>0 \mathrm{~kg}$ & $39(78.0)$ & $45(78.9)$ & 0.90 \\
\hline
\end{tabular}

Abbreviation: PPWR, postpartum weight retention; SD, standard deviation.

is considered elevated. ${ }^{13,14}$ of significant interest, we noted that $48 \%$ of all participants had $>5 \mathrm{~kg}$ of postpartum weight retention at 12 months postpartum compared with only $38 \%$ at 4 to 12 weeks' postpartum in our study, suggesting that future evaluations and interventions for postpartum weight retention will need to target a time period beyond the first 12 postpartum weeks. Our rates of postpartum weight retention $>5 \mathrm{~kg}$ at 12 months were also significantly higher than other estimates (20\%). ${ }^{14,15}$ However, Endres et al reported that $47.4 \%$ of women who participated in a national five-site prospective cohort study retained more than 10 pounds at 1 year postpartum. ${ }^{1}$ Our findings may be partially explained by our high-risk population including low-income minority women (32.2\% Hispanic and 52.1\% non-Hispanic black), women with prepregnancy obesity (42\%), and greater than $50 \%$ of women with excessive gestational weight gain, all of which have been associated with excessive postpartum weight retention.

In light of the current and prior studies, new ways to approach weight management in postpartum women are needed to improve the health of women and their families. Over the last decade, multiple studies have supported the role of patient navigators, especially as it relates to cancer prevention through survivorship. ${ }^{16-20}$ In general, these programs have primarily assisted medically underserved patients to overcome barriers to care including financial, logistical, system, cultural, and personal factors that contribute to delay or failure to obtain treatment. For these reasons, patient navigation may be a mechanism to improve outcomes for women in this postpartum transition period. However, the data from this analysis suggest this particular navigation intervention may require adaptation to improve postpartum weight outcomes.

Our study is timely given the recent focus on redesigning and optimizing postpartum care or the "fourth 
trimester" for our patients. ${ }^{21}$ The components of postpartum care encompass several domains such as mood, infant care, contraception, and health maintenance. The American College of Obstetricians and Gynecologists also recommends that providers counsel postpartum women with "actionable guidance regarding resumption of physical activity and attainment of healthy weight." Successful components of lifestyle interventions that target postpartum weight retention include frequent contact via text message or phone calls, face-to-face interactions, or interval contact via web application. ${ }^{22}$ Highly effective components of weight management interventions, in general, include calorie and physical activity goals, self-monitoring, cognitive behavioral therapy, and frequent provider-patient contact. ${ }^{23}$ To our knowledge, none of the published postpartum weight retention trials used a patient navigator to deliver the intervention content. We identified one protocol for a home-based childhood obesity intervention scheduled to be delivered by patient navigators. ${ }^{24}$ In this 16-session, 25-hour program, patient navigators will offer hands-on opportunities for skill building and provide detailed education and counseling to families by offering sessions about reading food labels, grocery store outings, and cooking demonstrations. Programs such as this one could be adapted to the unique transition period experienced by postpartum women, if demonstrated to be efficacious. These tasks are also well suited for trained patient navigators, as demonstrated in our mixed-method analysis of communication between navigators and participants. $^{12}$

\section{Limitations}

We recognize several limitations to this study including its small sample size and single site setting of English-speaking women. Thus, the findings may not be applicable to all populations. We also had a wider time period ( 12 weeks12 months postpartum) for our secondary postpartum weight-retention outcome, but this was necessary due to irregular contact with the health care system after the initial postpartum visit. Only women who had prepregnancy weights or returned for care within 12 months of delivery at this site could be included, thus also increasing the risk for bias as women without weight measurements could not be studied. However, the number of women in the historical control and navigated group was similar, suggesting that the missing weight data were similar for both groups. Lastly, the NNM program was not designed to be a weight-focused intervention. Navigator training did not specifically include education on nutrition, diet, or weight loss but instead focused on appointment scheduling, psychological support, communication with health providers, and the benefits of contraception and breastfeeding. Further, only a subgroup of women were actively receiving care at this site during the 12 weeks to up to 12 months of postpartum period; other women may have not been receiving medical care or receiving care at other sites which may have introduced ascertainment bias.

\section{Conclusion}

Although patient navigation is a promising intervention to improve women's health care utilization, in this particular navigation program, participation in postpartum patient navigation was not associated with postpartum weight retention in the early postpartum period (up to 12 weeks) or first year postpartum. This study provides initial information on the relationship between patient navigators and postpartum weight retention. Future studies that evaluate patient navigators and postpartum weight retention can focus on adaptations to patient navigation that incorporate weight management goals for women whose health and lifestyles change rapidly in a very-short-time period. Additional work may also specifically focus on providing services to women at greatest risk of postpartum weight retention, such as lowincome minority women and women with obesity or other comorbidities.

\section{Support}

The Navigating New Motherhood program was supported by the Northwestern Memorial Foundation/Friends of Prentice FY2015 Grants Initiative. LMY is supported by the NICHD K12 HD050121-11.

\section{Presentation}

This paper was presented at the Society of Maternal Fetal Medicine Annual Meeting (Las Vegas, NV) as a poster presentation (abstract ID: 343) during February 11 to 16, 2019.

\section{Conflicts of Interest}

The authors report no conflicts of interest.

\section{References}

1 Endres LK, Straub H, McKinney C, et al; Community Child Health Network of the Eunice Kennedy Shriver National Institute of Child Health and Human Development. Postpartum weight retention risk factors and relationship to obesity at 1 year. Obstet Gynecol 2015;125(01):144-152

2 Deputy NP, Sharma AJ, Kim SY, Hinkle SN. Prevalence and characteristics associated with gestational weight gain adequacy. Obstet Gynecol 2015;125(04):773-781

3 Villamor E, Cnattingius S. Interpregnancy weight change and risk of adverse pregnancy outcomes: a population-based study. Lancet 2006;368(9542):1164-1170

4 Rasmussen KM, Yaktine AL, Institute of Medicine; National Research Council, eds. Weight Gain During Pregnancy: Reexamining the Guidelines. Washington, DC: National Academics Press; 2009

5 Crozier SR, Robinson SM, Borland SE, Godfrey KM, Cooper C, Inskip HM; SWS Study Group. Do women change their health behaviours in pregnancy? Findings from the Southampton Women's Survey. Paediatr Perinat Epidemiol 2009;23(05):446-453

6 Inskip HM, Crozier SR, Godfrey KM, Borland SE, Cooper C, Robinson SM; Southampton Women's Survey Study Group. Women's compliance with nutrition and lifestyle recommendations before pregnancy: general population cohort study. BMJ 2009;338:b481

7 Phelan S, Brannen A, Erickson K, et al. 'Fit Moms/Mamás Activas' internet-based weight control program with group support to reduce postpartum weight retention in low-income women: study protocol for a randomized controlled trial. Trials 2015; 16:59 
8 Hales CM, Carroll MD, Fryar CD, Ogden CL. Prevalence of obesity among adults and youth: United States, 2015-2016. NCHS Data Brief 2017;(288):1-8

9 Oken E, Kleinman KP, Belfort MB, Hammitt JK, Gillman MW. Associations of gestational weight gain with short- and longerterm maternal and child health outcomes. Am J Epidemiol 2009; 170(02):173-180

10 McKenney KM, Martinez NG, Yee LM. Patient navigation across the spectrum of women's health care in the United States. Am J Obstet Gynecol 2018;218(03):280-286

11 Yee LM, Martinez NG, Nguyen AT, Hajjar N, Chen MJ, Simon MA. Using a patient navigator to improve postpartum care in an urban women's health clinic. Obstet Gynecol 2017;129(05):925-933

12 Strohbach A, Hu F, Martinez NG, Yee LM. Evaluating the use of text message communication in a postpartum patient navigation program for publicly insured women. Patient Educ Couns 2019;102 (04):753-759

13 AbuSabha R, Greene G. Body weight, body composition, and energy intake changes in breastfeeding mothers. JHum Lact 1998;14(02):119-124

14 Olson CM, Strawderman MS, Hinton PS, Pearson TA. Gestational weight gain and postpartum behaviors associated with weight change from early pregnancy to $1 \mathrm{y}$ postpartum. Int J Obes Relat Metab Disord 2003;27(01):117-127

15 Keppel KG, Taffel SM. Pregnancy-related weight gain and retention: implications of the 1990 Institute of Medicine guidelines. Am J Public Health 1993;83(08):1100-1103

16 Simon MA, Tom LS, Nonzee NJ, et al. Evaluating a bilingual patient navigation program for uninsured women with abnormal screening tests for breast and cervical cancer: implications for future navigator research. Am J Public Health 2015;105(05):e87-e94
17 Simon MA, Samaras AT, Nonzee NJ, et al. Patient navigators: Agents of creating community-nested patient-centered medical homes for cancer care. Clin Med Insights Womens Health 2016; 9:27-33

18 Battaglia TA, Darnell JS, Ko N, et al. The impact of patient navigation on the delivery of diagnostic breast cancer care in the National Patient Navigation Research Program: a prospective meta-analysis. Breast Cancer Res Treat 2016;158(03): 523-534

19 Rodday AM, Parsons SK, Snyder F, et al. Impact of patient navigation in eliminating economic disparities in cancer care. Cancer 2015;121(22):4025-4034

20 Ramachandran A, Snyder FR, Katz ML, et al; Patient Navigation Research Program Investigators. Barriers to health care contribute to delays in follow-up among women with abnormal cancer screening: data from the Patient Navigation Research Program. Cancer 2015;121(22):4016-4024

21 ACOG Committee Opinion No. ACOG committee opinion no. 736: optimizing postpartum care. Obstet Gynecol 2018;131(05): e140-e150

22 Dalrymple KV, Flynn AC, Relph SA, O'Keeffe M, Poston L. Lifestyle Interventions in overweight and obese pregnant or postpartum women for postpartum weight management: a systematic review of the literature. Nutrients 2018;10(11):E1704

23 Phelan S, Jankovitz K, Hagobian T, Abrams B. Reducing excessive gestational weight gain: lessons from the weight control literature and avenues for future research. Womens Health (Lond) 2011;7(06):641-661

24 Yun L, Boles RE, Haemer MA, et al. A randomized, home-based, childhood obesity intervention delivered by patient navigators. BMC Public Health 2015;15:506 